\title{
Distinct Localization of Renin and Angiotensins in Separate Subcellular Fractions of the Rat Adrenal Cortex
}

\author{
Kenji MIZUNO, Soitsu FUKUCHI* and TADASHi INAGAMI \\ Department of Biochemistry, Vanderbilt University School of \\ Medicine, Nashville, TN 37232, USA, and *Third Department of \\ Internal Medicine, Fukushima Medical College, Fukushima \\ 960-12, Japan.
}

\begin{abstract}
The subcellular localization of renin and immunoreactive angiotensins I and II was studied in rat adrenal cortical tissues. The identity of the immunoreactive angiotensins was confirmed as angiotensin I and angiotensin II by radioimmunoassay and high-performance liquid chromatography, respectively, with reference to standard compounds. By differential centrifugation of tissue homogenate in $0.25 \mathrm{M}$ sucrose $/ 30 \mathrm{mM}$ Tris- $\mathrm{HCl} / \mathrm{l} \mathrm{mM} \mathrm{EDTA,} \mathrm{pH} 7.4$, specific immunoreactive renin was found to be localized principally $(60 \%)$ in the mitochondrial fraction $\left(\mathrm{P}_{2}\right)$, whereas about $40 \%$ of both angiotensins I and II was contained in the soluble fraction; only $18-20 \%$ of both peptides was contained in the $\mathrm{P}_{2}$ fraction. On Percoll density gradient centrifugation of $\mathrm{P}_{2}$, renin was fractionated mostly in a denser band whereas angiotensins I and II were contained in a lighter density area closely corresponding to mitochondrial and lysosomal marker enzymes. These results suggest that renin and angiotensins in the cells of the rat adrenal gland reside in different subcellular compartments and argue against intracellular formation of angiotensins by renin in renin granules.
\end{abstract}

Key words: Renin, Angiotensin I, Angiotensin II, Adrenal cortex, Rat.

(Endocrinol Japon 38: 655-660, 1991)

\begin{abstract}
RECENT STUDIES have revealed the presence of immunoreactive specific renin in the adrenal gland of various mammalian species [1-5]. Besides renin, angiotensin converting enzyme has been shown to exist in the adrenal tissues [6], suggesting intraadrenal production of angiotensins. It was also demonstrated that adrenal renin is primarily located in the zona glomerulosa cells rather than the fasciculata or medullary cells $[7,8]$. Further, adrenal renin has been reported to increase markedly after high potassium loading or after nephrectomy $[8,9]$, where plasma renin activity was at undetectable levels. These findings suggest that adrenal renin is not merely due to contamina-
\end{abstract}

Received: July 11, 1991

Accepted: November 22, 1991

Correspondence to: Dr. Kenji MIZUNo, Third Department of Internal Medicine, Fukushima Medical College, I Hikari-gaoka, Fukushima 960-12, Japan. tion by plasma renin of renal origin, but endogenous to the adrenal. In support of this notion, renin mRNA has been detected in the adrenal gland [10], providing firmer evidence for the production of the enzyme in this tissue.

However, the functional significance of renin in the adrenal is not clear. Previously, we demonstrated renin-containing specific granules in the rat adrenal cortex and release of renin from the tissue in a regulated fashion [11]. On one hand, the limited data available suggested that the renin is involved in the production of aldosterone, presumably through intraadrenal generation of angiotensin II (Ang II) by renin [8, 9], but no clear evidence of such a function of renin in this tissue has yet been obtained.

In this study, as a step toward gaining a better insight into the mechanism of local formation of Ang II by intraadrenal renin, we examined the 
subcellular compartmentalization of angiotensin I (Ang I) and Ang II, and renin in the rat adrenal cortex.

\section{Materials and Methods}

Subcellular fractionation of renin and angiotensins by differential centrifugation

Male Sprague-Dawley rats weighing 180-220 g had been fed on normal sodium diet chow for a week. The adrenal glands were removed immediately after the rats were perfused with icecold saline (approximately $150 \mathrm{ml}$ ) to eliminate possible contamination by plasma components. The adrenal capsules from 10 rats were then prepared by manual compression and homogenized gently in $6 \mathrm{ml}$ of $0.25 \mathrm{M}$ sucrose $/ 30 \mathrm{mM}$

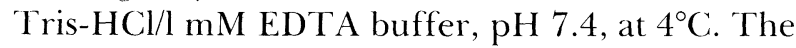
crude homogenate was then subjected to subsequent fractionation. After separating the unbroken cells, cell debris and capsular fragments $\left(\mathrm{P}_{0}\right)$ by centrifugation of the homogenate at $70 \times \mathrm{g}$ for $10 \mathrm{~min}$, the pellet obtained in this step was homogenized again in $3 \mathrm{ml}$ of the sucrose solution and recentrifuged at $600 \times \mathrm{g}$ for $10 \mathrm{~min}$ to remove the nuclear fraction $\left(\mathrm{P}_{1}\right)$, from the pellet. The supernatant $(9 \mathrm{ml})$ was combined and further centrifuged at $5,200 \times \mathrm{g}$ for $20 \mathrm{~min}$ to obtain a heavy mitochondrial fraction $\left(\mathrm{P}_{2}\right)$ in the pellet. The $\mathrm{P}_{2}$ pellet was washed twice by resuspension in the sucrose solution and re-centrifugation at $5,200 \times \mathrm{g}$ for $20 \mathrm{~min}$. The resulting supernatant $\left(\mathrm{S}_{2}, 15 \mathrm{ml}\right.$ ) was centrifuged at $12,000 \times \mathrm{g}$ for $20 \mathrm{~min}$ to obtain a light mitochondrial fraction $\left(\mathrm{P}_{2^{\prime}}\right)$, and the supernatant was further centrifuged at $105,000 \times \mathrm{g}$ for $60 \mathrm{~min}$ to separate the microsomal fraction (M) from the cytosolic fraction (S).

\section{Density gradient centrifugation}

The $\mathrm{P}_{2}$ pellet was gently dispersed in $1 \mathrm{ml}$ of the sucrose solution, and $0.5 \mathrm{ml}$ of the solution was added to $7.5 \mathrm{ml}$ of $35 \%(\mathrm{v} / \mathrm{v})$ Percoll (Sigma Chemical Co., St. Loius, USA) containing $0.25 \mathrm{M}$ sucrose, $1 \mathrm{mM}$ EDTA and $30 \mathrm{mM}$ Tris- $\mathrm{HCl}, \mathrm{pH}$ 7.4. The Percoll gradient was initiated by centrifugation at $30,000 \times \mathrm{g}$ for $30 \mathrm{~min}$. After centrifugation, the sample was fractionated into 10 fractions $(0.8 \mathrm{ml}$ each) by pipetting.
Measurement of renin activity, marker enzymes and protein concentration

Specific immunoreactive renin activity in samples from differential centrifugation and Percoll density gradient centrifugation was measured by the method previously reported [4, 12, 13], with nephrectomized rat plasma as the substrate. The Ang I produced was assayed by radioimmunoassay [14]. Succinate dehydrogenase activity [15] and acid phosphatase activity [16] were measured as a mitochondrial and lysosomal marker, respectively. The protein concentration was determined by the method of Lowry et al. [17] with bovine serum albumin (BSA) as standard.

Measurement of angiotensins and identification by high-performance liquid chromatography (HPLC)

Samples were mixed vigorously with (0.1 vol of $1 \mathrm{~N} \mathrm{HCl}$ and the mixture was centrifuged at $100,000 \times \mathrm{g}$ for $60 \mathrm{~min}$. The clear supernatant was applied to an octadecasilyl-silica cartridge (SepPak $\mathrm{C}_{18}$, Waters Associates, Milford, USA) which had been equilibrated with $0.1 \%$ trifluoroacetic acid (TFA). After rinsing with the same acid and then with distilled water, angiotensins were eluted with the mixture of methanol: distilled water: TFA (80:19.1:0.1, vol ratio). The eluate was evaporated to dryness in a vacuum centrifuge and resuspended in $0.1 \mathrm{M}$ Tris-acetate buffer containing 2.6 $\mathrm{mM}$ EDTA, $1 \mathrm{mM}$ phenylmethanesulfonyl fluoride, and $0.1 \%$ BSA, pH 7.4, for radioimmunoassay. The Ang II antiserum showed less than $1 \%$ cross-reactivity with Ang I but 100\% crossreactivity with angiotensin III (Ang III; Ang-(2-8) heptapeptide), Ang-(3-8) hexapeptide, and Ang(4-8) pentapeptide.

Samples for HPLC were redissolved in $0.1 \%$ TFA and applied to a reverse-phase HPLC column (Nova Pak $\mathrm{C}_{18}, 0.39 \times 15 \mathrm{~cm}$, Waters Associates). The column was eluted with $10 \mathrm{mM}$ sodium acetate buffer, pH 5.6, containing 28\% (v/v) methanol as a starting buffer followed by an exponential gradient of methanol concentration from $28 \%$ to $80 \%$ over a period of 13 min at a flow rate of $1 \mathrm{ml} / \mathrm{min}$. The eluate was collected in a fraction collector at intervals of $12 \mathrm{sec}$. Each fraction was evaporated to dryness in a vacuum centrifuge, and the sample was resuspended in the Tris-acetate buffer, $\mathrm{pH}$ 7.4, and subjected to radioimmunoassay of Ang I and II. The column was calibrated with synthetic Ang I, II, III, (3-8) 
hexapeptide, and (4-8) pentapeptide as standards.

\section{Results}

In order to determine whether angiotensin-like immunoreactive substances in the adrenal are indeed angiotensins, the sample prepared from tissue homogenate was examined by HPLC. The Ang II immunoreactive substance was eluted in a sharp, single peak at the position where standard Ang II emerges. Ang I immunoreactivity also emerged as a single peak at a position where standard Ang I appears. Although a very small

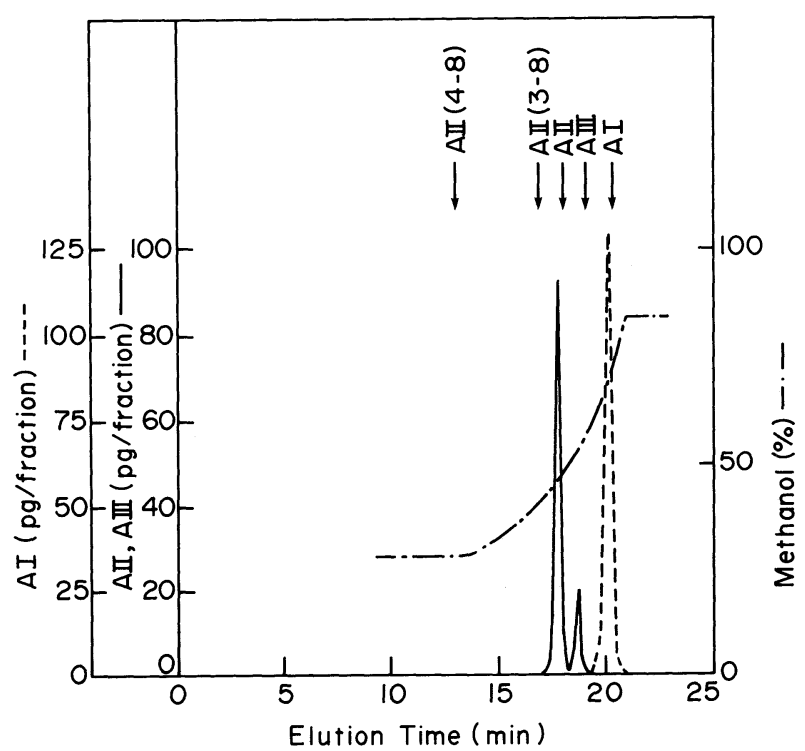

Fig. 1. High-pressure liquid chromatography (HPLC) elution profile of sample extracted from adrenal capsular homogenate. Synthetic angiotensins I, II, III and truncated compounds were used for calibration of the column. Elution time of angiotensin II was 17.8 \pm 0.1 $\min (n=3)$. amout of Ang III immunoreactivity was detected at the position where the peptide emerges, no immunoreactivity of Ang-(3-8) hexapeptide and Ang-(4-8) pentapeptide was detected in the sample (Fig. 1).

Table 1 gives the average distribution of renin, Ang I and Ang II and protein in the subcellular fractions obtained by differential centrifugation of the homogenate from rat adrenal cortical tissues. Approximately $60 \%$ of total renin activity which was recovered from all fractions $\left(\mathrm{P}_{0}\right.$ to $\left.\mathrm{S}\right)$ was contained in $\mathrm{P}_{2}$, which was identified as a mitochondrial fraction by measuring succinate dehydrogenase activity (not shown). The specific activity of renin in the $\mathrm{P}_{2}$ was $10.65 \mathrm{ng}$ of Ang $\mathrm{I} / \mathrm{h} / \mathrm{mg}$ protein. On the other hand, while more than $40 \%$ of total Ang I and II content was found in $\mathrm{S}_{2}$, less than $20 \%$ of total peptide content was found in $\mathrm{P}_{2}$. Thus, the percentage distribution of Ang II was very similar to that of Ang I, but very dissimilar to that of renin, as shown in Fig. 2. On Percoll density gradient centrifugation of the $P_{2}$ pellet, both Ang I and Ang II were found in lower density fractions corresponding to peaks of mitochondrial and lysosomal markers, whereas most renin activity was found in a denser region, clearly distinct from the peptide-containing fractions. In addition, it was also demonstrated that the renin-rich band was distinct from mitochondria and lysosomes, as shown in Fig. 3.

\section{Discussion}

The data reported herein confirm the previous observations indicating that the adrenal contains specific renin, Ang I and Ang II. The subcellular distribution pattern of Ang II was very similar to

Table 1. Subcellular localization of renin, angiotensin I and angiotensin II in rat adrenal capsular tissue

\begin{tabular}{clccrccc}
\hline & \multicolumn{7}{c}{ Fractions obtained by differential centrifugation } \\
\cline { 2 - 8 } & \multicolumn{1}{c}{$\mathrm{P}_{0}$} & \multicolumn{1}{c}{$\mathrm{P}_{1}$} & \multicolumn{1}{c}{$\mathrm{P}_{2}$} & \multicolumn{1}{c}{$\mathrm{S}_{2}$} & \multicolumn{1}{c}{$\mathrm{P}_{2}$} & $\mathrm{M}$ & $\mathrm{S}$ \\
\hline Renin & $0.54 \pm 0.11$ & $0.17 \pm 0.01$ & $13.21 \pm 0.32$ & $2.11 \pm 0.42$ & $1.90 \pm 0.17$ & $1.41 \pm 0.17$ & $1.21 \pm 0.64$ \\
Angiotensin II & $31.4 \pm 0.3$ & $30.8 \pm 7.9$ & $73.0 \pm 22.2$ & $157.2 \pm 17.6$ & $27.4 \pm 4.0$ & $32.5 \pm 4.8$ & $27.4 \pm 3.6$ \\
Angiotensin II & $25.7 \pm 1.2$ & $11.8 \pm 0.2$ & $56.1 \pm 9.6$ & $148.7 \pm 21.9$ & $39.3 \pm 11.6$ & $14.2 \pm 3.3$ & $12.1 \pm 2.1$ \\
Protein & $0.78 \pm 0.21$ & $0.53 \pm 0.10$ & $1.24 \pm 0.02$ & $2.10 \pm 0.51$ & $0.41 \pm 0.06$ & $0.50 \pm 0.10$ & $1.90 \pm 0.70$
\end{tabular}

Units are ng angiotensin $\mathrm{I} / \mathrm{h}$ for renin, pg for angiotensins I and II, and $\mathrm{mg}$ for protein. Values are means \pm SEM of three independent experiments. $\mathrm{P}_{0}=$ unbroken cells and cell debris, $\mathrm{P}_{1}=$ nuclear fraction, $\mathrm{P}_{2}=$ heavy mitochondrial fraction, $\mathrm{S}_{2}=$ second soluble fraction, $\mathrm{P}_{2^{\prime}}=$ light mitochondrial fraction, $\mathrm{M}=$ microsomal fraction, $S=$ soluble fraction. 

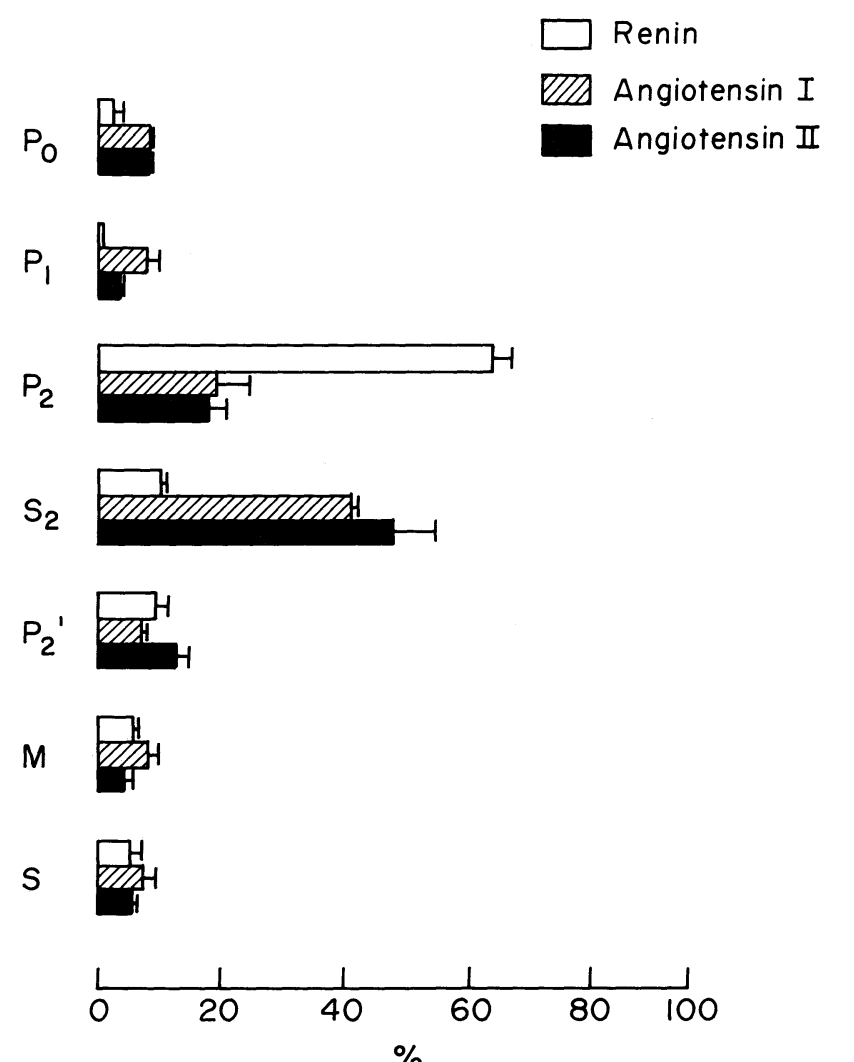

Fig. 2. Distribution patterns of renin and angiotensins I and II in fraction obtained by differential centrifugation of adrenal capsular homogenate.

that of Ang I, but was obviously dissimilar to that of renin. This finding is in line with the recent observation of Urata et al. [18] who demonstrated different localization of renin-like activity and Ang II immunoreactive substance on discontinuous sucrose density gradient centrifugation of rat adrenal capsular homogenate. Taken collectively, these findings suggest that renin and angiotensins in the cells of the rat adrenal cortical tissues reside in different subcellular compartments. It is also suggested that since the majority of renin activity was found in the $\mathrm{P}_{2}$ pellet, the adrenal enzyme is associated with the mitochondrial fraction but not with other subcellular organelles, consistent with the notion that the renin is not due to plasma contamination and that the cytosol is not the principal site of storage of renin in the adrenal.

Recently, a new method for purification of renin granules from homogenate of rat kidney cortex by Percoll density gradient has been developed [19]. This method provides biochemical evidence for colocalization of renin and Ang I and II in renin

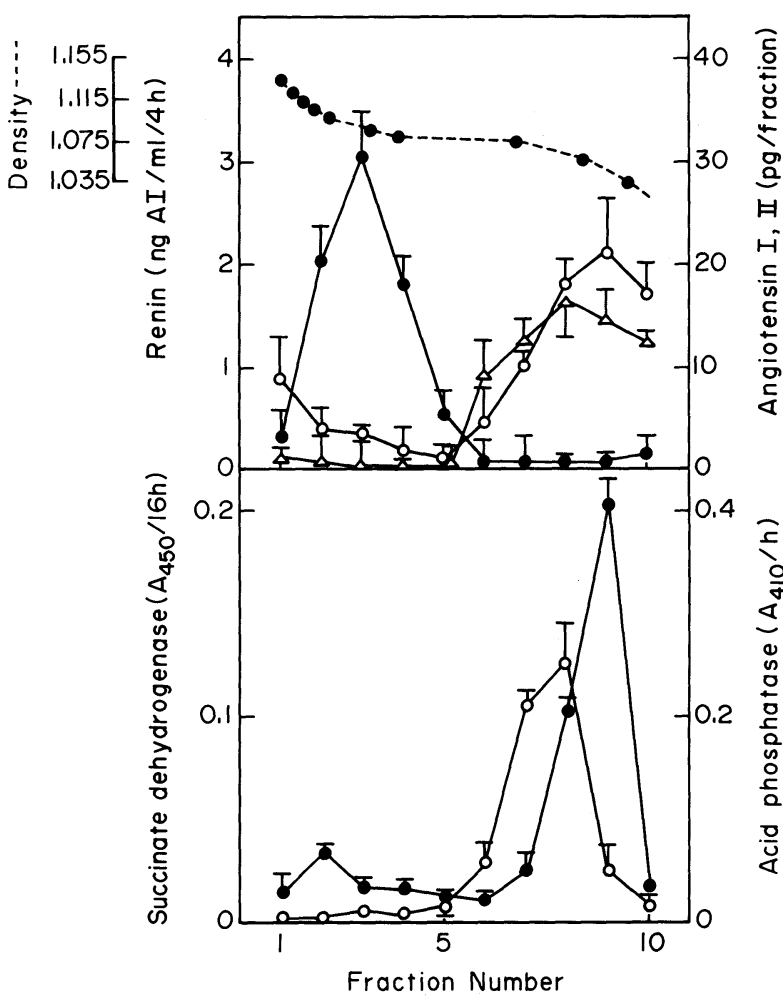

Fig. 3. Typical distribution of renin $(\bullet)$, angiotensins $I(\triangle)$ and II (O) [upper panel], and marker enzymes (acid phosphatase, 0 ; succinate dehydrogenase, $\bigcirc$ ) [lower panel] from the Percoll gradient of $\mathrm{P}_{2}$ pellet obtained from differential centrifugation. Fractions $(0.8 \mathrm{ml})$ were collected from the top of the centrifugation tube. In each fraction, renin, angiotensins I and II and marker enzymes' activities were measured as described in Methods. Values are means \pm SEM of 3 experiments.

granules prepared from the tissue [20]. In the present study, since relatively large amounts of Ang I and II were still found in the $P_{2}$ by using the same method, we further tested the hypothesis that angiotensins are produced within reninassociated compartments to be secreted into the soluble cytosolic fraction. Our results not only further support the notion that angiotensins are not localized in renin-containing compartments but also confirm that renin is stored within a granule-related structure.

While there are several lines of evidence that renin in extrarenal tissues plays a role in the production of angiotensins in some of these tissues by an intracellular mechanism [21-23], the present finding of separate localization of renin and angiotensins is in contrast to the coexistence of renin and angiotensins found in rat kidney renin 
granules in which Ang I is formed by renin. The separate compartmentalization of renin and angiotensins in the adrenal suggests the possibility that Ang II in the adrenal cortical cells is derived from plasma by an internalization mechanism mediated by the abundant Ang II receptors in the zona glomerulosa cells and results in accumulation in lysosomal fractions. However, this mechanism does not seem to explain the presence of Ang I or the absence of smaller degradation products of Ang II which may be produced by lysosomal peptidases. It is, therefore, possible that the adrenal synthesizes angiotensins via its own reninangiotensinogen system to store them in another particulate compartment at lower densities. Ang II formed may thus play a role in aldosterone production [24].

In summary, the present study demonstrates distinct localization of renin and angiotensins in subcellular compartments of rat adrenal cortical tissues. Although the possibility that these angiotensins are derived from plasma is not entirely eliminated, the coexistence of Ang I and Ang II, and the absence of fragments of these peptides, suggest intraadrenal generation of angiotensins, which may play a role as an aldosterone secretagogue.

\section{References}

1. Hayduck K, Boucher RR, Genest J (1970) Renin activity content in various tissues of dogs under different physio-pathological state. Proc Soc Exp Biol Med 134: 252-257.

2. Ganten D, Ganten U, Kubo S, Granzer P, Nowaczynski W, Boucher RR, Genest J (1974) Iso-renin in rat adrenal glands: influence of sodium, potassium and pituitary hormones. Am I Phisiol 227: 224-229.

3. Naruse M, Naruse K, Inagaki T, Inagami T (1984) Immunoreactive renin in mouse adrenal gland: localization in the inner cortical region. Hypertension 6: 275-280.

4. Naruse M, Sussman CR, Naruse K, Jackson RV, Inagami $\mathrm{T}$ (1983) Renin exists in human adrenal tissue. J Cilin Endocrinol Metab 57: 482-487.

5. Mizuno K, Ojima M, Hashimoto S, Tani M, Niimura S, Kunii N, Yabe R, Watari H, Inagami T, Fukuchi S (1987) Multiple forms of immunoreactive renin in human adrenocortical tumour tissue from patients with primary aldosteronism. Clin Sci 72: 699-704.

6. Plunkett IM, Correa FMA, Saavedra JM (1985) Quantitative autoradiographic determination of angiotensin converting enzyme binding in rat pituitary and adrenal glands with ${ }^{125} \mathrm{I}-351-\mathrm{A}$. Regul Pept 12: 263-272.

7. Doi, Y, Atarashi K, Franco-Saenz R, Murlow PJ (1983) Adrenal renin: a possible regulator of aldosterone production. Clin Exp Hypertens A5: $1119-1125$.

8. Doi Y, Atarashi K, Franco-Saenz R, Mulrow PJ (1985) Effect of changes in sodium or potassium balances, and nephrectomy on adrenal renin and aldosterone concentrations. Hypertensoin 6 (Suppl. I): I-24-I-29.

9. Nakamaru M, Misono KS, Naruse M, Workman
RJ, Inagami $\mathrm{T}$ (1985) A role for the adrenal renin-angiotensin system in the regulation of potassium-stimulated aldosterone production. Endocrinology 117: 1772-1778.

10. Ohkubo H, Nakayama K, Tanaka T, Nakanishi S (1986) Tissue distribution of rat angiotensinogen mRNA and structural analysis of its heterogeneity. J Biol Chem 261: 319-323.

11. Mizuno K, Hoffman LH, McKenzie JC, Inagami T (1988) Presence of renin secretory granules in rat adrenal gland and stimulation of renin secretion by angiotensin II but not by adrenocorticotropin. J Clin Invest 82: 1007-1016.

12. Mizuno K, Ojima M, Gotoh M, Hashimoto S, Fukuchi S (1985) True renin in human pituitary tissue. I Neurochem 44: 633-636.

13. Mizuno K, Ojima M, Hashimoto S, Fukuchi S (1985) Renin and angiotensin-converting enzyme in human neuroblastoma tissue. J Neuroche'm 45: $626-629$.

14. Haber E, Koerner T, Page LB, Kliman B, Purnode A (1969) Application of a radioimmunoassay for angiotensin I to the physiologic measurements of plasma renin activity in normal human subjects. $J$ Clin Endocrinol Metab 29: 1349-1355.

15. Slater EC, Bonner WD (1952) The effect of fluoride on the succinic oxidase system. Biochem J 52: $185-195$.

16. Ostrowski W, Tsugita A (1961) Purification of acid phosphomonoesterase from the human prostrate gland. Arch Biochem Biophys 94: 68-81.

17. Lowry OH, Rosebrough NJ, Farr AL, Randall RJ (1951) Protein measurement with the Folin phenol reagent. J Biol Chem 193: 265-275.

18. Urata H, Khosla MC, Bumpus FM, Husain A (1988) Evidence for extracellular, but not intracellular, generation of angiotensin II in the rat 
adrenal zona glomerulosa. Proc Natl Acad Sci USA 85: $825 \mathrm{l}-8255$.

19. Kawamura M, McKenzie JC, Hoffman LH, Tanaka I, Parmentier M, Inagami T (1986) The storage form of renin in renin granules from rat kidney cortex. Hypertension 8: 706-711.

20. Kawamura M, Nakamaru M, Inagami T (1985) Evidence for existence of angiotensins I and II in mature renin granules from rat kidney cortex. Biochem Biophys Res Commun 131: 628-633.

21. McKenzie JC, Naruse K, Inagami T (1985) The renin-angiotensin system in the rat anterior pituitary: colocalization of renin and angiotensin II in gonadotrophs. Anat Rec 212: 161-166.
22. Pandey KN, Inagami T (1986) Regulation of renin angiotensins by gonadotrophic hormones in cultured Leydig tumor cells: release of angiotensin but not renin. J Biol Chem 261: 3934-3989.

23. Mizuno K, Nakamaru M, Higashimori K, Inagami T (1988) Local generation and release of angiotensin II in peripheral vascular tissue. Hypertension 11 : 223-229.

24. Shier DN, Kusano E, Stoner GD, Franco-Saenz R, Mulrow PJ (1989) Production of renin, angiotensin II, and aldosterone by adrenal explant cultures: Response to potassium and converting enzyme inhibition. Endocrinology 125: 486-491. 